Full length article

\title{
The impact of implementing the WHO-2013 criteria for gestational diabetes mellitus on its prevalence and pregnancy outcomes: A comparison of the WHO-1999 and WHO-2013 diagnostic thresholds
}

\author{
Madena Shareef ${ }^{\mathrm{a}, 1}$, Langeza Saleh ${ }^{\mathrm{a}, \mathrm{b}, *, 1}$, Anton H. van den Meiracker $^{\mathrm{b}}$, Willy Visser ${ }^{\mathrm{a}, \mathrm{b}}$ \\ a Department of Obstetrics and Gynecology, Erasmus Medical Center, Rotterdam, the Netherlands \\ ${ }^{\mathrm{b}}$ Division of Vascular Medicine and Pharmacology, Department of Internal Medicine, Erasmus Medical Center, Rotterdam, the Netherlands
}

\section{A R T I C L E I N F O}

\section{Article history:}

Received 10 November 2019

Accepted 22 December 2019

Available online $\mathrm{xxx}$

\section{Keywords:}

Gestational diabetes mellitus

World Health Organization

Pregnancy outcomes

$75 \mathrm{~g}$ oral glucose tolerance test (OGTT)

\begin{abstract}
A B S T R A C T
Aims/hypothesis: To determine the impact of implementing the new WHO-2013 criteria on prevalence of gestational diabetes mellitus (GDM) and pregnancy outcomes compared to the WHO-1999 criteria. Methods: A retrospective study conducted in pregnant women who were referred to the Erasmus MC for an oral glucose tolerance test (OGTT) between 2010 and 2015.

Results: Of 3089 women, $11.5 \%(n=354)$ were diagnosed with GDM based on the WHO-1999 criteria and $17.0 \%(n=524)$ based on the 2013-criteria, with $97(3.1 \%)$ reclassified as non-GDM and $267(8.6 \%)$ reclassified as GDM when shifting from the 1999 to 2013-criteria. In contrast to $60 \%$ of patients in the WHO-2013 group, only $2 \%$ of the WHO-1999 group was diagnosed with GDM because of an elevated fasting glucose only. Patients reclassified as GDM by WHO-2013 criteria had a higher body mass index $(\mathrm{p}<0.001)$ and delivered babies with a higher birth weight $(\mathrm{p}=0.01)$. Maternal and neonatal adverse outcomes were comparable between patients with GDM based on WHO-1999 criteria and patients newly included by WHO-2013 criteria.

Conclusions: Implementing the new diagnostic criteria leads to a considerable increase of prevalence of GDM. The newly included patients were more frequently overweighed and delivered babies with a higher birth weight. The added diagnostic value of the fasting glucose threshold of the WHO-1999 criteria is very low compared to the 2-h post-OGTT threshold, supporting the use of a lower fasting glucose threshold value as advocated by the WHO-2013 criteria.

Tweet: The new WHO-2013 criteria leads to a considerable increase of prevalence of GDM.
\end{abstract}

(C) 2019 Published by Elsevier B.V.

\section{Introduction}

Gestational diabetes mellitus (GDM) is defined as new onset or first recognition of abnormal glucose tolerance during pregnancy [1]. The estimated prevalence of GDM in the Netherlands varies between 2-5\% [2]. Due to the rising epidemic of overweight, obesity and increase in mean maternal age the prevalence of GDM

Abbreviations: BMI, body mass index; CS, caesarean section; DM, diabetes mellitus; GDM, gestational diabetes mellitus; HAPO, Hyperglycemia and Adverse Pregnancy Outcomes study; IADPSG, The International Association of the Diabetes and Pregnancy Study Groups; LGA, large for gestational age; NICU, neonatal intensive care unit; OGTT, oral glucose tolerance test; PE, preeclampsia; PIH, pregnancy induced hypertension; SGA, small for gestational age; WHO, World Health Organization.

* Corresponding author at: Department of Internal Medicine, Room Ee1418, Erasmus Medical Centre, P.O. Box 2040, 3000 CA, Rotterdam, the Netherlands.

E-mail address: 1.saleh@erasmusmc.nl (L. Saleh).

1 These authors contributed equally. is rising and constitutes the most common metabolic complication during pregnancy [3-5].

Among the main consequences of GDM are increased risks of preeclampsia (PE), macrosomia and cesarean delivery and their associated morbidities [6]. In addition, higher placental passage of glucose can result in postnatal hyperinsulinemia and hypoglycemia in newborn infants potentially compromising neurodevelopmental outcomes [6]. Identifying pregnant women with GDM followed by frequent glucose monitoring and appropriate treatment, including dietary advices and/or insulin therapy and/or other glucose lowering medication, has reported to be associated with a decrease in macrosomia, shoulder dystocia, and PE [6].

Since GDM is mostly asymptomatic, laboratory screening is required for its detection. The Dutch Society of Obstetrics and Gynecology (NVOG) recommends screening at 24-28 weeks of gestation in pregnant women with risk factors for developing GDM and a first screening at 16 weeks gestation in women with a history of GDM [7,8]. 
The oral glucose tolerance test (OGTT) is most often used to diagnose GDM. The NVOG recommends a $75 \mathrm{~g}$ OGTT using the cut-off values of the World Health Organization (WHO) published in 1999: a fasting plasma glucose level (FG) $\geq 7.0 \mathrm{mmol} / \mathrm{L}$ or a $2-\mathrm{h}$ plasma glucose level ( $2 \mathrm{~h} \mathrm{G}$ ) of $\geq 7.8 \mathrm{mmol} / \mathrm{L}$ [7,8]. Following the HAPO study (Hyperglycemia and Adverse Pregnancy Outcomes), the International Association of the Diabetes and Pregnancy Study Groups (IADPSG) proposed new diagnostic criteria for GDM: $F G \geq 5.1 \mathrm{mmol} / \mathrm{L}, 1$-hr level of $\geq 10 \mathrm{mmol} / \mathrm{l}$ or a $2 \mathrm{hG}$ level $\geq 8.5 \mathrm{mmol} / \mathrm{L}$ [9]. Subsequently, the WHO adopted these new diagnostic criteria for GDM in 2013 [10]. Compared to the WHO-1999 criteria, the WHO-2013 criteria are based on a considerably lower threshold for fasting but a higher threshold for the 2 -h post loading glucose level.

The WHO-2013 criteria have not been implemented in the Netherlands yet. In a retrospective study, we investigated the consequences of applying WHO-2013 criteria on the prevalence of GDM and the incidence of adverse maternal and neonatal outcomes.

\section{Methods}

\section{Study participants}

A retrospective study was conducted of patients who underwent a 75-g OGTT from June 2010 to September 2015 at the Erasmus MC. Patients were referred by their midwife or by their gynecologist for a 75-g OGTT if they had one or more risk factors for GDM according to the Dutch national guideline [7]. Pregnant women with an abnormal OGTT according to the WHO-1999 criteria or the WHO-2013 criteria were eligible for analysis. Importantly, because GDM according to WHO-2013 was diagnosed retrospectively only women with a disturbed OGTT according to the WHO-1999 criteria were treated for GDM. Women with preexisting diabetes, twin pregnancy and a delivery outside of the Erasmus MC were excluded.

\section{Measurements}

Plasma glucose measurements were performed at the clinical laboratory of the Erasmus MC. Plasma glucose was measured by an enzymatic hexokinase method (Roche/Hitachi cobas c systems, Manheim, Germany).

\section{Outcomes and definitions}

Data on maternal characteristics, pregnancy and fetal outcomes were retrospectively collected from the patients' records. All data were incorporated in an anonymized database.

Maternal characteristics were age, parity, pre-gestational body mass index (BMI), positive family history of diabetes mellitus (DM), history of GDM, HbA1c levels and gestational age at OGTT.

The maternal outcomes were the following: HbA1c levels of the mother at time of diagnosis and delivery, treatment of GDM (dietary advices, insulin, oral medication or a combination), pregnancy induced hypertension (PIH) (systolic blood pressure $\geq 140 \mathrm{mmHg}$ and/or a diastolic blood pressure $\geq 90 \mathrm{mmHg}$ after 20 weeks of gestation in a previously normotensive woman), preeclampsia (PE) (gestational or pre-existing hypertension with de novo proteinuria ( $>300 \mathrm{mg} / 24 \mathrm{~h}$ ), mode of delivery (vaginal delivery, instrumental delivery, primary caesarean section (CS) or secondary $\mathrm{CS}$ ).

The fetal outcomes were the following: birth weight (grams), small for gestational age (SGA; birth weight <10th percentile corrected for gestational age, sex and parity), large for gestational age (LGA; birth weight >90th percentile corrected for gestational age, sex and parity), prematurity (delivery $<37$ weeks of gestation), shoulder dystocia, hyperbilirubinemia requiring phototherapy, neonatal hypoglycemia (blood glucose level $<2.6 \mathrm{mmol} / \mathrm{L}$ at least $3 \mathrm{~h}$ postpartum), admission to the neonatal intensive care unit (NICU), birth defects, need for respiratory support and mortality (intra-uterine or postpartum).

\section{Statistical analysis}

IBM SPSS Statistics 24 was used for the statistical analysis. The normality of continuous variables was assessed using the ShapiroWilk W-test. Continuous data between $>2$ groups were compared using ANOVA in case of normal distribution, the Kruskal Wallis in case of skewed distribution, with the Bonferroni correction in case of multiple comparisons. The chi-square test was used to compare categorical data among the groups. A p value less than 0.05 was considered statistically significant. Continuous variables are presented as median (range) and categorical data are presented as numbers (percentage).

\section{Results}

\section{Prevalence of GDM}

A total of 3165 OGTT's were carried out in 3089 subjects from June 2010 to September 2015. Thirteen patients with an abnormal OGTT according to the WHO-1999 criteria or the WHO-2013 criteria (respectively five and eight) had to be excluded from analysis due to lost to follow-up.

The prevalence of GDM was $11.5 \%(n=354)$ according to the WHO-1999 criteria, increasing to $17.0 \%(n=524)$ when the WHO2013 criteria were used. When shifting from old to new criteria, 97 women were reclassified as non-GDM (WHO-2013 excluded) and 267 women were reclassified as GDM (WHO-2013 included).

According to the WHO-1999 criteria $98 \%$ of patients were diagnosed with GDM because of an elevated 2-h and only $2 \%$ because of both an elevated fasting and 2-h post OGTT plasma glucose level. Consequently, all women diagnosed with GDM had an elevated 2-h post OGTT plasma glucose level. In the WHO 2013 group, 58 \% was diagnosed with GDM because of an elevated fasting plasma glucose, $21 \%$ because of an elevated 2-h plasma glucose and $21 \%$ because of both an elevated fasting glucose and 2-h glucose (Fig. 1). Consequently 79 \% could be diagnosed with GDM using a fasting plasma glucose level only when using the WHO-2013 criteria.

\section{Characteristics}

Age among the three groups was similar as was the history of GDM (Table 1). Women reclassified as non-GDM according to the WHO-2013 criteria were more often nulliparous than women reclassified as GDM $(p=0.02)$. The pregestational BMI of women who were reclassified as GDM was higher $(\mathrm{p}<0.001)$ than that of the two other groups (Table 1$)$. HbA1c levels were lower $(\mathrm{p}<0.001)$ in the WHO-2013 excluded group than in the WHO-1999 group.

The majority of the WHO-2013 included group were not treated for GDM, but treatment modalities for GDM between the WHO1999 and WHO-2013 group did not differ (Table 2). Gestational age at delivery among the three groups was similar as was the mode of delivery and occurrence of PE (Table 2). Cesarean sections were less often based on a maternal indication in the WHO-2013 excluded group. The birth weight in the newly included group was moderately higher than in the two other groups (Table 3), but the proportions of LGA neonates among the three groups did not differ. There were no differences between the groups in the prevalence of prematurity, shoulder dystocia, hyperbilirubinemia requiring phototherapy, admission to NICU, birth defects and need 


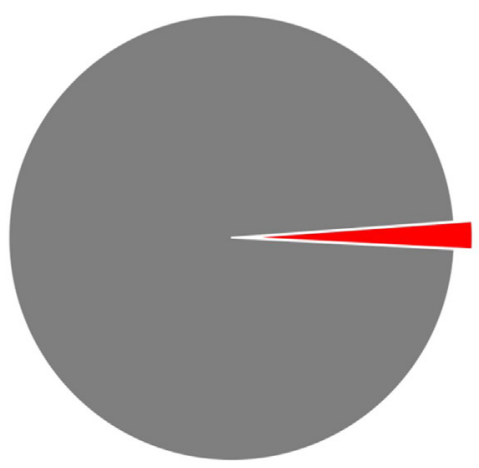

Diagnosis GDM based on

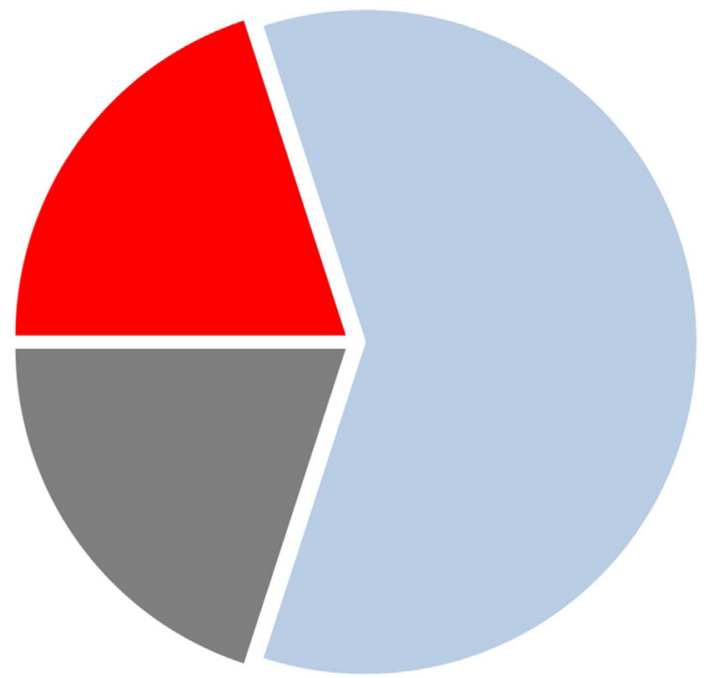

$\square$ Fasting glucose

- 2-hour glucose

- Fasting and 2-hour glucose

Fig. 1. Prevalence of GDM in the cohort according to both criteria.

Panel A: WHO-1999 criteria $(n=354)$ Panel B: WHO-2013 criteria $(n=524)$.

Table 1

Maternal characteristics.

\begin{tabular}{|c|c|c|c|c|c|c|}
\hline & WHO-1999 & $\begin{array}{l}\text { WHO-2013 } \\
\text { excluded }\end{array}$ & $\begin{array}{l}\text { WHO-2013 } \\
\text { included }\end{array}$ & $\begin{array}{l}\text { Column } 1 \\
\text { versus } 2\end{array}$ & $\begin{array}{l}\text { Column } 1 \\
\text { versus } 3\end{array}$ & $\begin{array}{l}\text { Column } 2 \\
\text { versus } 3\end{array}$ \\
\hline $\mathrm{N}$ & 354 & 97 & 267 & - & - & - \\
\hline Age, years & $34(20-47)$ & $32(20-45)$ & $33(18-46)$ & 0.177 & 0.999 & 0.731 \\
\hline Nulliparous & $116(32.8)$ & $39(40.2)$ & $72(27.0)$ & 0.185 & 0.134 & $0.020^{*}$ \\
\hline Pregestational BMI, $\mathrm{kg} / \mathrm{m}^{2}$ & $26.8(17-69)$ & $25.6(17-45)$ & $29.8(14-61)$ & 0.223 & $<0.001^{*}$ & $<0.001^{*}$ \\
\hline Positive family history of DM, $\mathrm{n}(\%)$ & $161(45.9)$ & $37(38.1)$ & $108(41.1)$ & 0.204 & 0.250 & 0.630 \\
\hline History of GDM, n (\%) & $39(11.1)$ & $8(8.3)$ & $36(13.5 \%)$ & 0.463 & 0.386 & 0.207 \\
\hline Gestational age at OGTT, weeks & $28(8-40)$ & $27(10-39)$ & $25(10-38)$ & 1.000 & $<0.001^{*}$ & $0.002^{*}$ \\
\hline \multicolumn{7}{|l|}{$\mathrm{HbA} 1 \mathrm{c}, \mathrm{mmol} / \mathrm{mol}$} \\
\hline At diagnosis & $36(19-73)$ & $33(19-43)$ & - & $<0.001^{*}$ & & \\
\hline At delivery & $36(21-56)$ & $34(21-41)$ & - & $0.003^{*}$ & & \\
\hline
\end{tabular}

BMI: Body mass index, DM: diabetes mellitus, GDM: gestational diabetes mellitus, OGTT: oral glucose tolerance test, *: statistically significant.

Table 2

Maternal outcomes.

\begin{tabular}{|c|c|c|c|c|c|c|}
\hline & WHO-1999 & $\begin{array}{l}\text { WHO-2013 } \\
\text { excluded }\end{array}$ & $\begin{array}{l}\text { WHO-2013 } \\
\text { included }\end{array}$ & $\begin{array}{l}\text { Column } 1 \\
\text { versus } 2\end{array}$ & $\begin{array}{l}\text { Column } 1 \\
\text { versus } 3\end{array}$ & $\begin{array}{l}\text { Column } 2 \\
\text { versus } 3\end{array}$ \\
\hline $\mathrm{N}$ & 354 & 97 & 267 & - & - & - \\
\hline \multicolumn{7}{|l|}{ Treatment, n (\%) } \\
\hline No treatment & $9(2.5)$ & $5(5.2)$ & $228(85.4)$ & 0.320 & $<0.001^{*}$ & $<0.001^{*}$ \\
\hline Diet and lifestyle advice & $224(63.3)$ & $69(71.1)$ & $25(9.4)$ & 0.186 & $<0.001^{*}$ & $<0.001^{*}$ \\
\hline Oral medication & $11(3.1)$ & $1(1.0)$ & $2(0.7)$ & 0.322 & $0.049^{*}$ & 0.793 \\
\hline Insulin treatment & $110(31.1)$ & $22(22.7)$ & $12(4.5)$ & 0.130 & $<0.001^{*}$ & $<0.001^{*}$ \\
\hline Weeks of insulin treatment & $8(1-25)$ & $7(1-23)$ & $3(1-19)$ & 0.428 & 0.111 & 1.000 \\
\hline $\mathrm{PIH}, \mathrm{n}(\%)$ & $31(8.8)$ & $5(5.2)$ & $19(7.1)$ & 0.296 & 0.552 & 0.636 \\
\hline $\mathrm{PE}, \mathrm{n}(\%)$ & $17(4.8)$ & $3(3.1)$ & $8(3.0)$ & 0.587 & 0.306 & 1.000 \\
\hline GA at delivery, weeks & $38.7(25.6-41-3)$ & $38.9(25.6-41.3)$ & $39.0(19.0-41.7)$ & 1.000 & 0.965 & 1.000 \\
\hline \multicolumn{7}{|l|}{ Mode of delivery, n (\%) } \\
\hline Vaginal delivery & $238(67.2)$ & $69(71.1)$ & $180(67.4)$ & 0.539 & 1.000 & 0.526 \\
\hline Primary cesarean delivery & $76(21.5)$ & $18(18.6)$ & $55(20.6)$ & 0.575 & 0.843 & 0.768 \\
\hline Secondary cesarean delivery & $41(11.6)$ & $10(10.3)$ & $33(12.4)$ & 0.602 & 0.904 & 0.714 \\
\hline Instrumental delivery & $53(15.0)$ & $11(11.3)$ & $34(12.7)$ & 0.415 & 0.484 & 0.857 \\
\hline \multicolumn{7}{|c|}{ Indication for cesarean section, $\mathrm{n}(\%)$} \\
\hline Prolonged first stage of labor & $28(24.1)$ & $5(17.9)$ & $16(18.2)$ & 0.619 & 0.390 & 1.000 \\
\hline Elective & $49(42.2)$ & $12(42.9)$ & $35(39.8)$ & 1.000 & 0.775 & 0.827 \\
\hline Maternal indication & $13(11.2)$ & $0(0.0)$ & $15(17.0)$ & 0.073 & 0.304 & $0.020^{*}$ \\
\hline Fetal indication & $26(22.4)$ & $11(39.3)$ & $22(25.0)$ & 0.059 & 0.740 & 0.156 \\
\hline
\end{tabular}

PIH: pregnancy induced hypertension, PE: pre-eclampsia, GA: gestational age, *: statistically significant. 
Table 3

Fetal outcomes.

\begin{tabular}{|c|c|c|c|c|c|c|}
\hline & WHO-1999 & $\begin{array}{l}\text { WHO-2013 } \\
\text { excluded }\end{array}$ & $\begin{array}{l}\text { WHO-2013 } \\
\text { included }\end{array}$ & $\begin{array}{l}\text { Column } 1 \\
\text { versus } 2\end{array}$ & $\begin{array}{l}\text { Column } 1 \\
\text { versus } 3\end{array}$ & $\begin{array}{l}\text { Column } 2 \\
\text { versus } 3\end{array}$ \\
\hline $\mathrm{N}$ & 354 & 97 & 267 & - & - & - \\
\hline Birth weight, $g$ & $3338(800-4950)$ & $3315(800-4950)$ & $3520(138-5080)$ & 1.000 & 0.014 & 0.010 \\
\hline SGA & $32(9.0)$ & $10(10.3)$ & $22(8.2)$ & 0.844 & 0.775 & 0.676 \\
\hline LGA & $48(13.6)$ & $11(11.3)$ & $49(18.4)$ & 0.615 & 0.118 & 0.150 \\
\hline Prematurity (<37 weeks), n (\%) & $40(11.3)$ & $8(8.2)$ & $30(11.2)$ & 0.461 & 1.000 & 0.447 \\
\hline Shoulder dystocia, $\mathrm{n}(\%)$ & $8(2.3)$ & $1(1.0)$ & $9(3.4)$ & 0.691 & 0.461 & 0.301 \\
\hline $\begin{array}{l}\text { Hyperbilirubinemia requiring } \\
\text { phototherapy, n (\%) }\end{array}$ & $19(5.4)$ & $3(3.1)$ & $24(9.0)$ & 0.437 & 0.082 & 0.070 \\
\hline Neonatal hypoglycemia, n (\%) & $78(22.0)$ & $19(19.6)$ & - & 0.677 & - & $-*$ \\
\hline Admission to NICU, $\mathrm{n}(\%)$ & $61(17.2)$ & $16(16.5)$ & $51(19.1)$ & 0.881 & 0.598 & 0.648 \\
\hline Birth defects, n (\%) & $39(11.0)$ & $11(11.3)$ & $22(8.2)$ & 1.000 & 0.278 & 0.409 \\
\hline Respiratory support, n (\%) & $16(4.5)$ & $7(7.2)$ & $15(5.6)$ & 0.299 & 0.579 & 0.620 \\
\hline \multicolumn{7}{|l|}{ Mortality, n (\%) } \\
\hline Intra uterine & $1(0.3)$ & $0(0.0)$ & $2(0.7)$ & 1.000 & 0.580 & 0.608 \\
\hline Neonatal & $5(1.4)$ & $3(3.1)$ & $3(1.1)$ & 0.377 & 1.000 & 0.348 \\
\hline
\end{tabular}

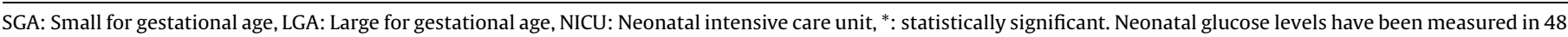
$\%$ of the cases in the WHO-2013 included group.

for respiratory support, nor was there a difference in mortality (Table 3).

Of the newly included group, 76 women with an initially negative OGTT according to WHO-1999 underwent a second OGTT, as recommended for symptomatic women and women with a history of GDM [7]. Of these women, 30 had a positive OGTT according to the WHO-1999 criteria and were treated for GDM. The second OGTT was done at a median of seven weeks later than the first OGTT and a relatively large proportion of these women (37 \%) delivered a LGA neonate.

\section{Discussion}

This retrospective cohort study shows the impact on the prevalence and pregnancy outcomes of GDM when shifting from the WHO-1999 to the WHO-2013 criteria. Implementing the new criteria results in a major increase in GDM prevalence, which is in accordance to previous reports [11-14]. The newly included women were more overweighed and delivered neonates with a higher birth weight. In addition, the proportion of LGA neonates tended to be higher in the newly included group. Previous studies also have shown that women diagnosed with the revised criteria are more likely to be overweighed [14,16].

In agreement with previous observations (15) our finding shows that the added value of the fasting glucose of the WHO-1999 criteria to diagnose GDM is disappointingly low as only $2 \%$ of our patients with GDM had a fasting plasma glucose level above the threshold of $\geq 7.0 \mathrm{mmol} / \mathrm{L}$. This finding is a strong argument for lowering the fasting glucose threshold as recommended by the WHO-2013 criteria and results in a marked reduction in the number of OGTTs to be performed, which not only is beneficial for the patient but also saves costs. Indeed with application of the new diagnostic criteria an OGTT could have been avoided in almost $80 \%$ of our patients [15]. Women excluded by the WHO-2013 criteria had lower HbA1c levels than women in the WHO-1999 group, indirectly supporting the view that exclusion of these women was appropriate.

The reason for a cesarean section was less often because of a maternal indication in the WHO-2013 excluded group. This may suggest that maternal comorbidities are less often prevalent in this group, which is reasonable because of the lower BMI in this group of excluded women.

The rate of neonatal hypoglycemia was hardly comparable since the majority of the babies delivered in the WHO-2013 included group did not have routinely glucose monitoring.
Thirty-nine women with an initially undisturbed OGTT according to WHO-1999 criteria were treated for GDM (Table 2). In 30 of these women, treatment was started because of a disturbed OGTT at a second occasion. The indication for the treatment in the other nine women was a high random glucose level. On the other hand, nine women, while having a disturbed OGTT according to WHO-1999 criteria, were not treated for GDM because they were diagnosed after 37 weeks gestation and therefore delivery was chosen instead of starting treatment.

Neonates delivered by women with a delayed diagnosis and hence a delay in treatment were more often large for gestational age. These women were treated for a shorter amount of time. One may wonder if the proportion of LGA and macrosomia would have been lower if no delay in diagnosis had occurred, since appropriate management of GDM is associated with a lower birth weight [6]. Indeed, Koning et al., have reported that treating women equally for GDM based either on WHO-2013 or WHO-1999 criteria results in a similar proportion of LGA neonates [17]. Since patients with GDM according to the WHO-2013 criteria make up $22 \%$ of all LGA pregnancies, this might be an adequate endpoint for defining OGTT threshold values [12].

In the WHO-1999 group $2.5 \%$ of patients and in the WHO-2013 included group $85.4 \%$ of patients were not treated for GDM. Despite this large difference in treatment, almost no difference in maternal or fetal/neonatal outcomes between these two groups was observed. This absent difference in outcomes is likely explained by the fact that with the OGGT screening the majority of patients has a mild form of GDM as also reflected by the relatively low HbA1c value.

\section{Limitations}

Not all data of all women could be collected from the patients' records, related to the retrospective design of the study. Furthermore, the OGTT's were carried out in women with one or more risk factors for GDM. The prevalence of GDM found in our study is therefore not a reflection of that in the general obstetric population. Finally, women of the WHO-2013 included group were not diagnosed with GDM and the majority of therefore not treated for this condition, thereby limiting the comparison of outcomes between this group and the WHO-1999 group. Of note, maternal and fetal/neonatal outcomes between the WHO-1999 and the WHO2013 excluded group were comparable, probably for earlier mentioned reasons. Neonatal glucose levels have been measured 
in $48 \%$ of the cases in the WHO-2013 included group because GDM was not diagnosed or treated in most patients of this group.

\section{Conclusion}

Implementing the new diagnostic criteria leads to a considerable increase in the prevalence of GDM, with the newly included women being more frequently overweighed delivering babies with a higher birth weight. The relatively high fasting glucose threshold of the 1999-WHO criteria has a very low added value to diagnose GDM, favoring the use of a lower fasting plasma glucose threshold as advocated by the WHO-2013 criteria, thereby reducing the number of OGTTs.

Prospective, randomized studies are needed to determine whether the newly included women equally benefit from treatment and whether women that will be excluded by the new criteria could be safely left untreated.

\section{Declaration of Competing Interest}

The authors have no conflict of interest.

\section{References}

[1] American Diabetes A. Diagnosis and classification of diabetes mellitus. Diabetes Care 2014;37(Suppl. 1):S81-90.

[2] van Leeuwen M, Prins SM, de Valk HW, Evers IM, Visser GH, Mol BW. [Gestational diabetes mellitus: treatment reduces the risk of complications] Diabetes gravidarum. Behandeling vermindert kans op complicaties. Ned Tijdschr Geneeskd 2011;155:A2291.

[3] Dabelea D, Snell-Bergeon JK, Hartsfield CL, Bischoff KJ, Hamman RF, McDuffie RS, et al. Increasing prevalence of gestational diabetes mellitus (GDM) over time and by birth cohort: kaiser permanente of Colorado GDM screening program. Diabetes Care 2005;28:579-84.

[4] Getahun D, Nath C, Ananth CV, Chavez MR, Smulian JC. Gestational diabetes in the United States: temporal trends 1989 through 2004. Am J Obstet Gynecol 2008;198:e521-5 525 .
[5] Bardenheier BH, Elixhauser A, Imperatore G, Devlin HM, Kuklina EV, Geiss LS, Correa A. Variation in prevalence of gestational diabetes mellitus among hospital discharges for obstetric delivery across 23 states in the United States. Diabetes Care 2013:36:1209-14.

[6] Hartling L, Dryden DM, Guthrie A, Muise M, Vandermeer B, Donovan L. Benefits and harms of treating gestational diabetes mellitus: a systematic review and meta-analysis for the U.S. Preventive Services Task Force and the National Institutes of Health Office of Medical Applications of Research. Ann Intern Med 2013;159:123-9, doi:http://dx.doi.org/10.7326/0003-4819-159-2201307160-00661.

[7] Diabetes mellitus and pregnancy. Clinical guideline version 2.0 http://nvogdocumenten.nl/index.php?pagina=/richtlijn/item/pagina.php\&richtlijn_id $=863$.

[8] Alberti KG, Zimmet PZ. Definition, diagnosis and classification of diabetes mellitus and its complications. Part 1: diagnosis and classification of diabetes mellitus provisional report of a WHO consultation. Diabet Med 1998;15:539-53.

[9] International Association of, P. Pregnancy Study Groups Consensus D, Metzger BE, Gabbe SG, Persson B, Buchanan TA, Catalano PA, et al. International association of diabetes and pregnancy study groups recommendations on the diagnosis and classification of hyperglycemia in pregnancy. Diabetes Care 2010;33:676-82.

[10] Diagnostic criteria and classification of hyperglycaemia first detected in pregnancy: a World Health Organization Guideline. Diabetes Res Clin Pract 2014:103:341-63.

[11] O’Sullivan EP, Avalos G, O’Reilly M, Dennedy MC, Gaffney G, Dunne F, et al. Atlantic Diabetes in Pregnancy (DIP): the prevalence and outcomes of gestational diabetes mellitus using new diagnostic criteria. Diabetologia 2011:54:1670-5.

[12] Ryan EA. Diagnosing gestational diabetes. Diabetologia 2011;54:480-6.

[13] Agarwal MM. Gestational diabetes mellitus: an update on the current international diagnostic criteria. World J Diabetes 2015;6:782-91.

[14] Koning SH, van Zanden JJ, Hoogenberg K, Lutgers HL, Klomp AW, Korteweg FJ, et al. New diagnostic criteria for gestational diabetes mellitus and their impact on the number of diagnoses and pregnancy outcomes. Diabetologia 2018:61:800-9.

[15] Agarwal MM, Dhatt GS, Punnose J. Gestational diabetes: utility of fasting plasma glucose as a screening test depends on the diagnostic criteria. Diabet Med 2006;23:1319-26.

[16] Laafira A, White SW, Griffin CJ, Graham D. Impact of the new IADPSG gestational diabetes diagnostic criteria on pregnancy outcomes in Western Australia. Aust N Z J Obstet Gynaecol 2016;56:36-41.

[17] Koning SH. Gestational diabetes mellitus: diagnosis and outcome. the Netherlands: University of Groningen; 2017. 